\title{
Intracranial Infection Caused by Multidrug-resistant Acinetobacter Baumannii
}

Haiyong He $M D^{1}$ iD, Manting Li $M D^{2}$ iD, Ying Guo $M D^{3}$ (iD), Lun Luo $M D^{4}$ (D),

Robin Bhattarai $P h D^{5}$ iD, Wensheng $\mathrm{Li}^{\mathrm{M}} \boldsymbol{D}^{\mathbf{6}}$ iD

1,2,3,4,6 Department of Neurosurgery, Third Affiliated Hospital of Sun Yat-sen University, Guangzhou, Guangdong, PR China ${ }^{5} \mathrm{~B} \& \mathrm{C}$ Medical College Teaching Hospital \& Research Centre Pvt. Ltd., Birtamode, Nepal

Date of submission: $27^{\text {th }}$ June 2021

Date of acceptance: $3^{\text {rd }}$ November 2021

Date of publication: $1^{\text {st }}$ December 2021

\begin{abstract}
Introduction: We report the successful treatment of a patient who, following vestibular schwannoma resection, developed intracranial infection caused by multidrug-resistant Acinetobacter baumannii (MRAB).

Case Presentation: The patient was diagnosed with multidrug-resistant Acinetobacter baumannii infection based on clinical manifestations and cerebrospinal fluid (CSF) culture. The treatment included external ventricular drainage, posterior fossa decompressive craniectomy, endoscopic lavage for fourth ventricle, subdural drainage, and intravenous injection/ ventricular irrigation of sulperazone. The MRAB-induced intracranial infection was successfully cured. The follow-up lasted for 84 months, and the patient has resumed normal life and work.

Conclusion: Active individualized treatment should be administered at the earliest. The drainage of CSF, ventricular lavage, and proper choice of antibiotics are key to treat intracranial infections caused by multidrug-resistant Acinetobacter baumannii.
\end{abstract}

Key words: CSF drainage, Intracranial infection, Intrathecal injection, Multidrug-resistant Acinetobacter baumannii, Ventricular lavage.

\section{Introduction}

V entriculitis and meningitis are known complications following neurosurgical procedures. Recently, the number of multidrug-resistant Acinetobacter baumannii (MRAB) is steadily rising, ${ }^{1}$ and this makes the treatment extremely difficult, resulting in the mortality rate as high as $15-71 \% .^{2}$ The treatment of intracranial Acinetobacter baumannii infections is made difficult by multidrug-

Access this article online
Website: https://www.nepjol.info/index.php/NJN
DOI: https://doi.org/10.3126/njn.v18i4.39401
HOW TO CITE
He H, Li M, Guo Y, Luo L, Bhattarai R, Li W. Intracranial Infection
Caused by Multidrug-resistant Acinetobacter Baumannii. NJNS.
2021;18(4):59-63.

Address for correspondence:

Dr. Wensheng Li

Department of Neurosurgery,

Third Affiliated Hospital of Sun Yat-sen University,

Tianhe district, Guangzhou,

Guangdong Province, 510630, PR China

E-mail: sums3neuro@126.com

Phone: +86-013902260029

Copyright (C) 2021 Nepalese Society of Neurosurgeons (NESON)

ISSN: 1813-1948 (Print), 1813-1956 (Online)

(7) This work is licensed under a Creative Commons Attribution-Non Commercial 4.0 International License. resistance and poor drug penetration through the bloodbrain barrier. Herein, we report a successfully treated case with intracranial infection of MRAB, along with a review of recent literature.

\section{Case Report}

\section{The first operation and postoperative treatment}

A 45-year-old female underwent left vestibular schwannoma resection via retrosigmoid approach on 24 July 2014 (Figure 1). On the seventh post-operative day, she developed delirium, chills, low fever and neck rigidity. A lumbar puncture revealed cerebrospinal fluid (CSF) turbidity and massive flocculation. The pressure of lumbar puncture was $110 \mathrm{mmH}_{2} \mathrm{O}$, the concentration of CSF white blood cells was $8200 \times 10^{6} / \mathrm{L}$, the percentage of neutrophils was $95 \%$, and the concentration of sugar and proteins was $0.01 \mathrm{mmol} / \mathrm{L}$ and $1.92 \mathrm{~g} / \mathrm{L}(0.15-0.4)$, respectively. Empirical intravenous (IV) antibiotics (meropenem, 2.0 q8h; vancomycin,1.0 q12h) were started, and CSF replacement by lumbar puncture (replaced with $30 \mathrm{ml}$ saline each time) was administered.

The second operation and postoperative conditions

On 4 August 2014, the patient deteriorated into coma, and CT indicated hydrocephalus (Figure 2). A right frontal external ventricular drain (EVD) was urgently placed to drain infected CSF (Figure 3). After surgery, the patient became conscious. 


\section{He et al}

The third operation and postoperative conditions

On 5 August 2014, the patient went into a coma again. Cranial MRI indicated tonsillar hernia, ventriculitis and meningitis (Figure 4), for which posterior fossa decompressive craniectomy, endoscopic lavage for fourth ventricle and subdural drainage were urgently carried out (Figure 5). CSF culture (CSF sample sent on 31 July 2014) revealed A. baumannii resistant to cephalosporin, gentamicin, carbapenems and ticarcillin (Table 1). Therefore, meropenem was replaced by sulperazone (a combination of cefoperazone and sulbactam) (3.0 gm, iv infusion q6h) postoperatively. On 6 August 2014, intraventricular lavage with sulperazone (q8h) was performed (irrigation fluid: $500 \mathrm{ml}$ saline $+0.075 \mathrm{~g}$ sulperazone; pump: Terufusion infusion pump TE-135, Japan), by pumping $10 \mathrm{ml}$ (20 drops per min) of the irrigation fluid into the EVD, and diverting $10 \mathrm{ml}$ out from the subdural drainage tube of the posterior cranial fossa. By repeated in and out pumping, the ventricle was washed by $120 \mathrm{ml}$ fluid each time, and the patient showed stable vital signs during the irrigation. On 8 August 2014, the patient regained consciousness. CSF from EVD became clear and CSF sugar and cell counts normalised within next 2 weeks. On 21 August 2014, intraventricular lavage was stopped. Intrathecal (IT) sulperazone $(75 \mathrm{mg} / 5 \mathrm{ml})$ was done daily, the EVD was clapped for $2 \mathrm{~h}$ and then opened. On 31 August 2014, EVD was removed, and the posterior fossa subdural drainage tube was closed. The patient occasionally vomited, which improved by mannitol dehydration. The subdural drainage tube was removed on the next day.

\section{The postoperative conditions}

From 13 to 15 September, multiple CSF analysis revealed a non-meningitis picture and CSF cultures were sterile. The patient was subsequently treated with lumbar peritoneal shunt (LPS) for hydrocephalus (Figure 5). The patient did not develop a fever postoperatively, and was discharged on 25 September 2014.

The follow-up lasted for 84 months. The patient resumed normal life and work.

\begin{tabular}{|c|c|c|c|}
\hline & Antimicrobials & MIC & Drug Sensitivity* $^{*}$ \\
\hline 1 & Ampicillin & $>16$ & $\mathrm{R}$ \\
\hline 2 & Piperacillin & $>64$ & $\mathrm{R}$ \\
\hline 3 & Cefazolin & $>16$ & $\mathrm{R}$ \\
\hline 4 & Cefoxitin & $>16$ & $\mathrm{R}$ \\
\hline 5 & Cefuroxime & $>16$ & $\mathrm{R}$ \\
\hline 6 & Cefotaxime & $>32$ & $\mathrm{R}$ \\
\hline 7 & Ceftazidime & $>16$ & $\mathrm{R}$ \\
\hline 8 & Ceftriaxone & $>32$ & $\mathrm{R}$ \\
\hline 9 & Cefepime & $>16$ & $\mathrm{R}$ \\
\hline 10 & Aztreonam & $>16$ & $\mathrm{R}$ \\
\hline 11 & Meropenem & $>8$ & $\mathrm{R}$ \\
\hline 12 & Ertapenem & $>4$ & $\mathrm{R}$ \\
\hline 13 & Amoxicillin/Clavulanic & $>16 / 8$ & $\mathrm{R}$ \\
\hline 14 & Ticarcilline/Clavulanic & $>64$ & $\mathrm{R}$ \\
\hline 15 & Ciprofloxacin & $>2$ & $\mathrm{R}$ \\
\hline 16 & Levofloxacin & $>4$ & $\mathrm{R}$ \\
\hline 17 & Tobramicin & $>8$ & $\mathrm{R}$ \\
\hline 18 & Gentamicin & $>8$ & $\mathrm{R}$ \\
\hline 19 & Amikacin & $>32$ & $\mathrm{R}$ \\
\hline 20 & Tetracycline & $>8$ & $\mathrm{R}$ \\
\hline 21 & Cefotaxime/Clavulanic & $>4$ & $\mathrm{R}$ \\
\hline 22 & Ceftazidime/Clavulanic & $>2$ & $\mathrm{R}$ \\
\hline
\end{tabular}

Table 1: The results of drug sensitivity test for Acinetobacter baumannii/ haemolyticus in cerebrospinal fluid. Note *resistance $(R)$ 

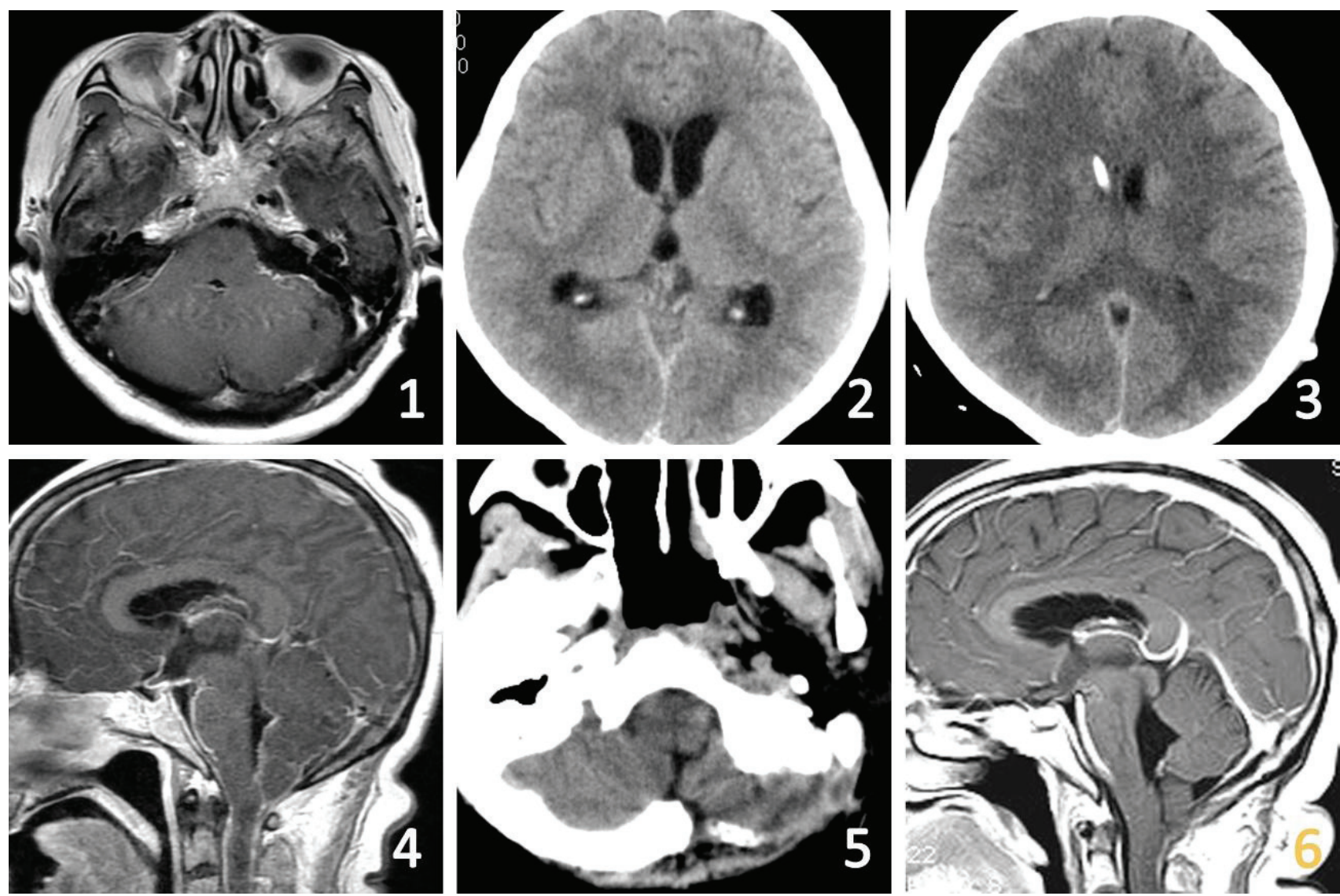

Figures (1) After left vestibular schwannoma resection, T1-weighted axial MRI indicated complete resection of the tumor, and the fourth ventricle did not show significant enlargement. (2) Head CT scan indicated hydrocephalus. (3) Head CT scan indicated the drainage tube of right ventricle was in position; the hydrocephalus was improved. (4) T1-weighted sagittal MRI scan indicated cerebellar tonsil hernia, meningitis and ventriculitis. (5) Head CT scan indicated the left occipital bone flap was removed, and the subdural drainage tube was in position. (6) T1-weighted sagittal MRI scan indicated the meninges and ventricle did not show significant enhancement.

\section{Discussion}

In the recent decade, $A$. baumannii has emerged as an important nosocomial infectious agent due to its ability to tolerate desiccation and to accumulate diverse mechanisms of resistance. MRAB associated with high mortality have become a new challenge for anti-infective treatment. ${ }^{2}$ The patient was infected after vestibular schwannoma resection. Blood, sputum and cerebrospinal fluid cultures showed MRAB. During the same period, no similar infection occurred in the ICU and operating room. Therefore, the patient's infection was considered to be related to perioperative management. Prevention is the most important, but when infected with MRAB ventriculitis or meningitis, treatment must be started immediately. IV/IT colistin significantly increased the cure rate and decreased the mortality of meningitis caused by MRAB ${ }^{4-10}$ However, colistins are nephrotoxic, ventricular irrigation might lead to chemical ventriculitis/meningitis, making it difficult to determine when to stop antibiotics and perform post-infectious hydrocephalus shunt. ${ }^{11}$
Tigecycline is also used for the treatment of A. baumannii infection. Since the blood-brain barrier permeability of this drug is low, the treatment should also be combined with IT injection. ${ }^{12}$ Nowadays, Tigecycline is often excluded from routine drug sensitivity tests in many Chinese hospitals. The price of Tigecycline is relatively high and it is not covered by the medical insurance, which further restricts its application.

The use of sulbactam-containing regimens may play a role in the treatment of infections caused by carbapenemresistant $A$. baumannii that remain susceptible to sulbactam. ${ }^{13-15}$ The recommended dose of sulbactam for the treatment of severe A baumannii infection is 9 to $12 \mathrm{~g}$ daily. However, the dosage of sulbactam was just $4.0 \mathrm{~g}$ daily in our patient's case (2:1 Cefoperazone/sulbactam, i.e. $12 \mathrm{~g}$ of sulperazone, contains $8 \mathrm{~g}$ of cefoperazone and $4 \mathrm{~g}$ of sulbactam). This is the maximum dose of sulbactam recommended for sulperazone. Therefore, intrathecal and intraventricular injection can increase blood concentration to treat intracranial MRAB infection. In this case, although a sensitivity test was not performed on sulbactam, the 


\section{He et al}

patient showed improved symptoms without serious complications and was cured with sulperazone. However, the number of $A$. baumannii strains resistant to sulbactam is gradually increasing; sensitivity tests on sulbactam should be promoted in order to prevent worsening of the infection.

IT instillation of antibiotics can achieve high intraventricular and the subarachnoid space concentration. Reducing intracranial pressure and drainage of infected CSF may be achieved via an EVD. ${ }^{20}$ After MRAB infection, CSF with high levels of proteins and floccules reduce the mobility, making it difficult for drugs to diffuse when delivered by lumbar puncture or EVD drainage. In such resistant cases, intraventricular lavage in combination with IV and IT antibiotics may help expedite eradication of resistant infection. The irrigation velocity was controlled by a micro-infusion pump. The dose of sulperazone in the irrigation fluid was $1 / 20$ of the single dose $(1.5 \mathrm{~g})$. The irrigation obtained good treatment outcomes and had no significant adverse reactions. The main purpose of ventricular lavage is to reduce inflammatory substances and bacterial load. We believe that in order to avoid or reduce the side effects caused by drug accumulation, the drug concentration of lavage should be as low as possible, or the warm saline with or without drugs should be lavaged. Finally, according to the recommended dose reported in the literature, intraventricular or intrathecal injection of drugs were done. After every injection, the CSF drain was temporarily closed for $2 \mathrm{~h}$ to prevent the untimely washout of the drug.

A large amount of cellulose deposit was observed in the fourth ventricle and cerebellopontine angle cistern using a ventriculoscope. Moreover, we hypothesized that lavage under ventriculoscope, which eliminated large amounts of inflammatory fibrous substances and reduced bacterial load, is more efficient in controlling infection and reducing postoperative adhesion. Based on our results, this route was well tolerated and had excellent outcomes. We think that early intraventricular lavage is very important for the control of the disease.

MRAB has made the treatment of intracranial infections challenging. It brings huge economical and psychological burden to the patients and their families. In order to avoid or decrease MRAB infections, prevention should be the first priority instead of treatment: aseptic operation should be strictly performed; invasive operation in the ICU should be avoided if possible; the use of antibiotics and drainage tubes, and the treatment of wounds should involve standardized management. ${ }^{22,23}$ Once MRAB infection is identified, individualized treatment should be administered at the earliest. The drainage of CSF, ventricular lavage, and proper choice of antibiotics are key to the treatment of intracranial infections caused by MRAB. We believe that these comprehensive measures (ventricular cistern lavage under ventriculoscope, timely drainage and decompression of bone flaps; ventricular lavage, intrathecal injection of lumbar puncture, etc.) could be important in managing these life-threatening MDR ventricular infections. Our patient was cured, which is similar to the previously reported cases. However, because this report only involved one patient, more studies must be conducted to demonstrate the therapeutic effects.

\section{Conclusions}

Intracranial infection of MRAB after neurosurgical procedures is difficult to treat, and has an extremely high mortality. Our recommendations for the management include prevention, individualized treatment (combined drug treatment with intrathecal injection) and ventricular irrigation at an early stage.

\section{Conflict of Interest: None}

Source(s) of support: This work was supported by the R \& D program of key fields in Guangdong Province under Grant number 2020b090924004.

\section{References}

1. Maraki S, Mantadakis E, Mavromanolaki VE, Kofteridis DP, Samonis G. A 5-year Surveillance Study on Antimicrobial Resistance of Acinetobacter baumannii Clinical Isolates from a Tertiary Greek Hospital. Infection \& Chemotherapy. 2016;48:190. https://doi.org/10.3947/ic.2016.48.3.190

2. Kim BN, Peleg AY, Lodise TP, Lipman J, Li J, Nation $\mathrm{R}$, Paterson DL. Management of meningitis due to antibiotic-resistant Acinetobacter species. Lancet Infect Dis. 2009;9:245-55. https://doi.org/10.1016/ S1473-3099(09)70055-6

3. Jasemi S, Douraghi M, Adibhesami H, Zeraati H, Rahbar M, Boroumand MA, Aliramezani A, Ghourchian S, Mohammadzadeh M. Trend of extensively drug-resistant Acinetobacter baumannii and the remaining therapeutic options: a multicenter study in Tehran, Iran over a 3-year period. Lett Appl Microbiol. 2016;63:466-472. https://doi.org/10.1111/ lam.12669

4. Kempf M, Rolain J. Emergence of resistance to carbapenems in Acinetobacter baumannii in Europe: clinical impact and therapeutic options. Int J Antimicrob Ag. 2012;39:105-114. https://doi. org/10.1016/j.ijantimicag.2011.10.004

5. Karaiskos I, Galani L, Baziaka F, Giamarellou H. Intraventricular and intrathecal colistin as the last therapeutic resort for the treatment of multidrugresistant and extensively drug-resistant Acinetobacter baumannii ventriculitis and meningitis: a literature 
review. Int J Antimicrob Ag. 2013;41:499-508 https://doi.org/10.1016/j.ijantimicag.2013.02.006

6. Dalgic N, Ceylan Y, Sancar M, Telhan L, Kafadar I, CavusogluH,CeylanO,HasimO.Successfultreatment of multidrug-resistant Acinetobacter baumannii ventriculitis with intravenous and intraventricular colistin. Ann Trop Paediatr. 2009;29:141-7. https:// doi.org/10.1179/146532809X440761

7. Cascio A, Conti A, Sinardi L, Iaria C, Angileri FF, Stassi G, David T, Versaci A, Iaria M, David A. Postneurosurgical multidrug-resistant Acinetobacter baumannii meningitis successfully treated with intrathecal colistin. A new case and a systematic review of the literature. Int J Infect Dis. 2010;14:e5729. https://doi.org/10.1016/j.ijid.2009.06.032

8. Karaiskos I, Galani L, Baziaka F, Katsouda E, Ioannidis I, Andreou A, Paskalis H, Giamarellou H. Successful treatment of extensively drug-resistant Acinetobacter baumannii ventriculitis and meningitis with intraventricular colistin after application of a loading dose: a case series. Int J Antimicrob Agents. 2013;41:480-3. https://doi.org/10.1016/j. ijantimicag.2013.02.010

9. De Bonis P, Lofrese G, Scoppettuolo G, Spanu T, Cultrera R, Labonia M, Cavallo MA, Mangiola A, Anile C, Pompucci A. Intraventricular versus intravenous colistin for the treatment of extensively drug resistant Acinetobacter baumannii meningitis. Eur J Neurol. 2016;23:68-75. https://doi.org/10.1111/ ene. 12789

10. Fotakopoulos G, Makris D, Chatzi M, Tsimitrea E, Zakynthinos E, Fountas K. Outcomes in meningitis/ventriculitis treated with intravenous or intraventricular plus intravenous colistin. Acta Neurochir (Wien). 2016;158:603-10. https://doi. org/10.1007/s00701-016-2702-y

11. Ng J, Gosbell IB, Kelly JA, Boyle MJ, Ferguson JK. Cure of multiresistant Acinetobacter baumannii central nervous system infections with intraventricular or intrathecal colistin: case series and literature review. J Antimicrob Chemoth. 2006;58:1078-1081. https://doi.org/10.1093/jac/dk1347

12. Stefani S, Dowzicky M. Assessment of the Activity of Tigecycline against Gram-Positive and GramNegative Organisms Collected from Italy between
2012 and 2014, as Part of the Tigecycline Evaluation and Surveillance Trial (T.E.S.T.). Pharmaceuticals. 2016;9:74. https://doi.org/10.3390/ph9040074

13. Viehman JA, Nguyen MH, Doi Y. Treatment Options for Carbapenem-Resistant and Extensively DrugResistant Acinetobacter baumannii Infections. Drugs. 2014;74:1315-1333. https://doi.org/10.1007/ s40265-014-0267-8

14. Jaruratanasirikul S, Wongpoowarak W, Wattanavijitkul T, Sukarnjanaset W, Samaeng M, Nawakitrangsan M, Ingviya N. Population Pharmacokinetics and Pharmacodynamics Modeling To Optimize Dosage Regimens of Sulbactam in Critically Ill Patients with Severe Sepsis Caused by Acinetobacter baumannii. Antimicrob Agents Chemother. 2016;60:7236-7244. https://doi. org/10.1128/AAC.01669-16

15. Ye JJ, Lin HS, Yeh CF, Wu YM, Huang PY, Yang CC, Huang CT, Lee MH. Tigecycline-based versus sulbactam-based treatment for pneumonia involving multidrug-resistant Acinetobacter calcoaceticusAcinetobacter baumannii complex. Bmc Infect Dis. 2016;16:374. https://doi.org/10.1186/s12879-0161717-6

16. Kumar A, Agrawal D, Sharma BS. The Role of Endoscopic Lavage in Recalcitrant MultidrugResistant Gram-Negative Ventriculitis Among Neurosurgical Patients. World Neurosurg. 2016;93:315-23. https://doi.org/10.1016/j. wneu.2016.06.022

17. Enoch DA, Summers C, Brown NM, Moore L, Gillham MI, Burnstein RM, Thaxter R, Enoch LM, Matta B, Sule O. Investigation and management of an outbreak of multidrug-carbapenem-resistant Acinetobacter baumannii in Cambridge, UK. J Hosp Infect. 2008;70:109-18. https://doi.org/10.1016/j. jhin.2008.05.015

18. Shrestha GS, Tamang S, Paneru HR, Shrestha PS, Keyal N, Acharya SP, Marhatta MN, Shilpakar $\mathrm{S}$. Colistin and tigecycline for management of external ventricular device-related ventriculitis due to multidrug-resistant Acinetobacter baumannii. J Neurosci Rural Pract. 2016;7:450-2. https://doi. org/10.4103/0976-3147.176194 